\title{
Research on Quantitative Evaluation Methods and Influencing Factors of Natural Gas Reservoir Development
}

\author{
Haitao Li $\mathbb{D}^{1},{ }^{1}$ Guo Yu $\left(\mathbb{D},{ }^{1}\right.$ Yanru Chen $\mathbb{D}^{1},{ }^{1}$ and Dongming Zhang $\mathbb{D}^{2}$ \\ ${ }^{1}$ Exploration and Development Research Institute, PetroChina Southwest Oil and Gas Field Company, Chengdu, \\ Sichuan 610041, China \\ ${ }^{2}$ State Key Laboratory of Coal Mine Disaster Dynamics and Control, Chongqing University, Chongqing 400044, China \\ Correspondence should be addressed to Dongming Zhang; zhangdm@cqu.edu.cn
}

Received 9 August 2021; Accepted 30 November 2021; Published 31 December 2021

Academic Editor: Xuesheng Liu

Copyright (c) 2021 Haitao Li et al. This is an open access article distributed under the Creative Commons Attribution License, which permits unrestricted use, distribution, and reproduction in any medium, provided the original work is properly cited.

Current methods of evaluating the effects of gas reservoir exploitation primarily focus on evaluating production statistics of a well or field, and they often have a certain subjectivity. In order to further analyze key indexes that affect a gas reservoir during production, this paper considered the characteristic parameters of different types of gas reservoirs and established an index system of evaluating a gas reservoir "exploitation effect" from the three aspects of gas reservoir characteristics, rock characteristics, and economic benefits. There are numerous factors affecting the exploitation effect of a gas reservoir. The relationships between different factors are complicated, and the evaluation result of each factor can also be vague. A fuzzy optimization theoretical model for gas reservoir evaluation and optimization was established on the basis of a quantitative study on the evaluation parameters in fuzzy mathematics. In order to clearly understand the influence of each factor on the gas reservoir exploitation effect, numerical simulation was used to perform a multifactor numerical simulation study of the quantitative sensitivity to determine the sequence of different influencing factors in terms of influencing the gas reservoir exploitation effect. This study provides a quantitative scientific basis for the evaluation of gas reservoir exploitation effect.

\section{Introduction}

Due to complex geological conditions in China, low-quality reserves account for a higher proportion of the proven natural gas reserves. The exploitation with scale benefits is faced with long-term challenges. Accordingly, the evaluation of the gas field exploitation effect has become critical for proper field evaluation. However, in traditional theories and technologies of gas reservoir engineering, there are relatively few contents in this aspect. This has gradually become the technical bottleneck of gas reservoir exploitation. Compared with developed countries, in China, the quantitative analysis that couples natural gas exploitation technologies with economic situation is still lacking, and it is difficult to meet the demand for exploiting conventional and unconventional complex gas reservoirs under the new normal situation. This restricts further improvement of the natural gas exploitation level in China.
A comprehensive evaluation of the gas reservoir exploitation effect is a seemingly simple problem, but in fact, it is complicated. Because there are numerous factors influencing this effect, the interactions and contradictions among the factors increase the difficulty of analysis. It needs to be studied and determined by effective multi-index quantitative comprehensive evaluation methods. Guo and Evans [1] established a net present value model for the economic benefit evaluation of horizontal well exploitation in naturally fractured reservoirs with dissolved gas flooding. Samuel et al. [2] established a simple net present value model to evaluate the economic benefits of horizontal well exploitation by using the steady-state production equation of oil wells. Liu et al. [3] established the calculation formulas of horizontal well exploitation, vertical well exploitation, and their relative payback periods, which have a certain guiding role in the exploitation and deployment of horizontal wells. Wang et al. [4] used the Upper Shaximiao Formation $\left(\mathrm{J}_{2} s_{2}\right)$ gas reservoir 
of the Middle Jurassic Series in the Xinchang Gas Field of the western Sichuan Depression as a representative. This study enhanced the geologic understanding of the reservoir by comparing the scattered distribution of the permeable reservoir sand body to the continuous distribution of favorable reservoirs. Three breakthroughs were determined in the production-increasing technology from multilayer fracturing of vertical wells to multilayer and multifracture fracturing of horizontal wells. In order to achieve efficient exploitation of a gas field, $\mathrm{Wu}$ et al. [5] performed a series of technical studies on the distribution and exploitation mode of organic reef reservoirs, including the fine characterization of small reefs and quantitative prediction of thin reservoirs, the optimization design of horizontal wells in band-like small reef gas reservoir, the real-time optimization and adjustment of horizontal well trajectory in ultradeep and thin reservoirs, and so on. Combined with the optimization exploitation technology policies that considered the influence of water invasion, Wang et al. [6] solved several key problems and developed a series of supporting exploitation technologies suitable for a gas reservoir. These were applied to the exploitation practice of a gas field. Dong et al. [7] studied the characteristics of the pore structure of natural gas hydrate reservoir in the Qilian Mountain Permafrost. Ding et al. [8] studied the sand control in a natural gas hydrate reservoir in the South China Sea. Sun et al. [9] proposed a new approach to efficient and safe gas production from unsealed marine hydrate deposits. Wang et al. [10] established a new analysis method of cumulative gas production per unit pressure drop, and its effectiveness was verified by its application in the calculation of reserves of three gas reservoirs. Hu et al. [11] believed that the developed special technology for the efficient exploitation of deep-marine carbonate gas reservoirs provided strong support for PetroChina Southwest Oil \& Gas Field to build a giant gas field of 10 billion cubic meters creating substantial growth of natural gas output. Wang et al. [12] developed a set of key technical systems suitable for the efficient exploitation of complex tight sandstone gas reservoirs in the Yan'an Gas Field located in the southeastern Ordos Basin. The Sulige Gas Field is located in the northern Ordos Basin, and it is China's largest tight sandstone gas field. After decades of research and integrated innovation, a full set of key technologies centered on reservoir characterization [13], full digital earthquake monitoring [14], big well group stereoscopic exploitation [15], "factory-like" fracturing transformation [16], downhole throttling [17], and drainage gas recovery has been developed for the exploration and development in this field [18]. These technologies have had field-scale exploitation implementation and provide a good reference for the exploitation of tight sandstone gas reservoirs in China [19-32].

In summary, many scholars have performed the technical and economic analysis and classified evaluation for different types of gas reservoirs and developed several empirical modes in terms of exploitation indexes such as reasonable gas well output, the reasonable well spacing density of gas reservoir, and reasonable gas producing rates. However, due to the complexity of geological conditions, the determination of exploitation indexes is still a relatively difficult technical step in the process of gas reservoir exploitation. Moreover, the evaluation methods of gas reservoir exploitation effect mostly look for influences based upon statistics, which are subjective to a certain extent, and cannot directly guide the optimization of specific indexes. Therefore, it is necessary to consider a variety of gas reservoir characteristic parameters and establish a comprehensive evaluation index system for gas reservoir development by combining statistics with the technical-economic coupling analysis method.

\section{Gas Reservoir Evaluation Index System}

In order to further analyze the important indexes affecting gas reservoirs, this paper separates the corresponding parameter values from the calculation formulas of geological reserves, dynamic reserves, gas well production, and economic return rates. The evaluation index system for the gas reservoir exploitation effect was established with consideration of the three aspects of gas reservoir characteristics, rock characteristics, and economic evaluation. A total of 12 indexes were used to evaluate the gas reservoir, as shown in Figure 1.

\section{Screening Model Based on the Fuzzy Optimization Theory}

3.1. Fuzzy Optimization Theory Model for Gas Reservoir Evaluation and Optimization. In fuzzy decision problems, the decision-making objectives and constraint conditions typically have collinearity, and there are no obvious differences between objects. The theory of fuzzy mathematics can well solve fuzzy decision problems and has been widely used in practice.

$X$ is a set composed of $n$ schemes. Namely, it is a domain of discourse as follows:

$$
X=\left\{x_{1}, x_{2}, \ldots, x_{n}\right\},
$$

where $x_{i}$ represents a certain candidate evaluation scheme and $i=1,2, \ldots, n$. Then, fuzzy optimization is to determine the membership degree $u_{A}\left(x_{i}\right)$ of each element $x_{i}$ to the "optimal solution."

$$
\begin{gathered}
u_{A}: X \longrightarrow[0,1], \\
x i \longrightarrow u_{A}\left(x_{i}\right) .
\end{gathered}
$$

The larger the membership degree, the closer the gas reservoir is to an "optimal gas reservoir." In other words, the problem of scheme optimization can be transformed into selecting a gas reservoir with the largest membership degree.

In general, the evaluation indexes can be divided into two categories: one consists of the-larger-the-better indexes and the other consists of the-smaller-the-better indexes. The membership degree of the-larger-the-better indexes can be calculated from the following:

$$
r_{i j}=\frac{x_{i j}-x_{i \min }}{x_{i \max }-x_{i \min }} .
$$

And the membership degree of the-smaller-the-better indexes can be calculated from the following: 


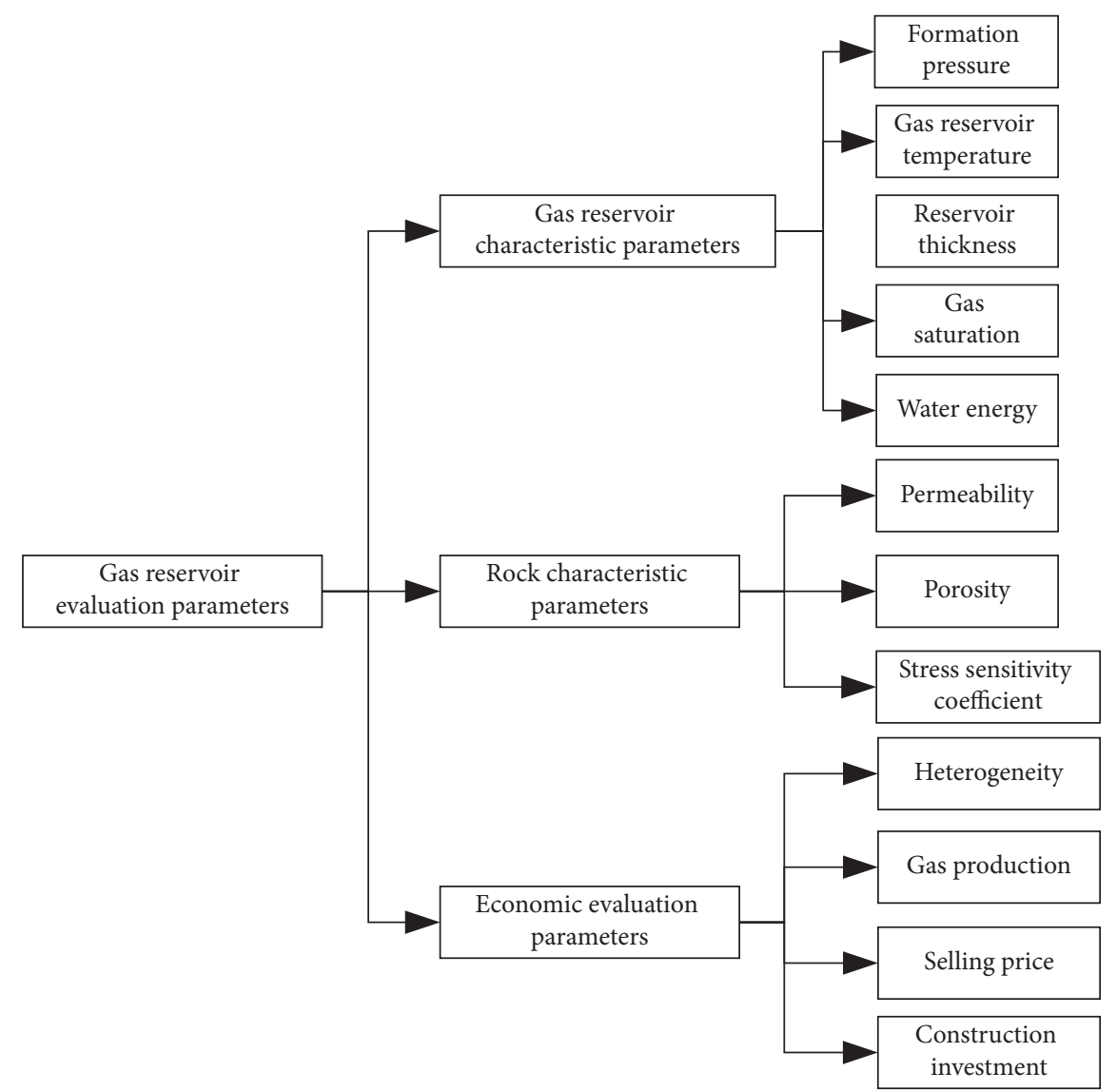

Figure 1: Gas reservoir evaluation index parameters.

$$
r_{i j}=\frac{x_{i \max }-x_{i j}}{x_{i \max }-x_{i \min }}
$$

where $r_{i j}$ represents the membership degree of the $j$-th evaluation index of gas reservoir $i, x_{\mathrm{ij}}$ represents the value of the $j$-th evaluation index of gas reservoir $i, x_{\text {jmin }}$ represents the minimum value of the $j$-th evaluation index, and $x_{\text {jmax }}$ represents the maximum value of the $j$-th evaluation index.

Thus, the matrix of the membership degree of each gas reservoir evaluation index $R_{i j}$ can be expressed as follows:

$$
R_{i j}=\left[\begin{array}{cccc}
r_{11} & r_{12} & \cdots & r_{1 m} \\
r_{21} & r_{22} & \cdots & r_{2 m} \\
\vdots & \vdots & \vdots & \vdots \\
r_{n 1} & r_{n 2} & \cdots & r_{n m}
\end{array}\right] .
$$

The degree of membership of each index of the optimal gas reservoir $\vec{G}$ can be obtained by evaluating the membership degree matrixes of the indexes. The maximum value among the membership degrees of each index for all gas reservoirs is the membership degree of the $m$-th index of the optimal gas reservoir $\vec{G}$. Thus, the optimal gas reservoir $\vec{G}$ can be expressed as follows:

$$
\begin{aligned}
\vec{G} & =\left(r_{11} \vee r_{12} \vee \cdots \vee r_{1 j}, r_{21} \vee r_{22} \vee \cdots \vee r_{2 j}, \ldots, r_{i 1} \vee r_{i 2} \cdots r_{i j}\right)^{T} \\
& =\left(g_{1}, g_{2}, \ldots, g_{m}\right) T .
\end{aligned}
$$

Similarly, the minimum value among the membership degrees of each index for all gas reservoirs is the membership degree of the $m$-th index of the inferior gas reservoir $\vec{B}$. Thus, the inferior gas reservoir $\vec{B}$ can be expressed as follows:

$$
\begin{aligned}
\vec{B} & =\left(r_{11} \wedge r_{12} \wedge \cdots \wedge r_{1 j}, r_{21} \wedge r_{22} \wedge \cdots \wedge r_{2 j}, \ldots, r_{i 1} \wedge r_{i 2} \cdots r_{i j}\right)^{T} \\
& =\left(b_{1}, b_{2}, \ldots, b_{m}\right) T,
\end{aligned}
$$

where $\vee$ is the maximum operator and $\wedge$ is the minimum operator.

Notably, different evaluation indexes have different influences on the evaluation results. The degree of influence of each index on the evaluation results can be expressed by their weight $\omega_{j}$, and then the weight vector of the $m$-th index $\vec{W}$ can be set as follows:

$$
\vec{W}=\left(\omega_{1}, \omega_{2}, \cdots, \omega_{m}\right),
$$

where $\omega_{i}$ represents the weight of the $j$-th index and $j=1,2$, $3, \ldots, m$. 
Gas reservoir $i$ can be expressed by the vector $\vec{R}_{i}$ as follows:

$$
\overrightarrow{R_{i}}=\left(r_{1 j}, r_{2 j}, \ldots, r_{n j}\right)^{T} .
$$

Then, the difference between the $i$-th gas reservoir and the optimal gas reservoir can be described by the off-optimal distance as follows:

$$
\left\|\vec{W}\left(\vec{G}-\overrightarrow{R_{i}}\right)\right\|=\sqrt[p]{\sum_{j=1}^{m}\left[\omega_{1}\left(g_{1 j}-r_{i j}\right)\right]^{p}} .
$$

Similarly, the difference between the $i$-th gas reservoir and the inferior gas reservoir can be described by the offinferior distance as follows:

$$
\left\|\vec{W}\left(\overrightarrow{R_{i}}-\vec{B}\right)\right\|=\sqrt[p]{\sum_{j=1}^{m}\left[\omega_{1}\left(r_{i j}-b_{1 j}\right)\right]^{p}} .
$$

For gas reservoir $x_{i}$, its membership degree to the optimal gas reservoir is $u_{A}\left(x_{i}\right)$, which is simplified as $u_{i}$, and its membership degree to the inferior gas reservoir is $u_{B}\left(x_{i}\right)$, which is simplified as $u_{i}^{c}$. Then, $u_{i}$ and $u_{i}^{c}$ have the following relationship:

$$
u_{i}^{c}=1-u_{i}
$$

In fuzzy theory, the membership degree can be viewed as a weight. The weighted off-optimal distance can be defined as $u_{i}\left\|\vec{W}\left(\vec{G}-\overrightarrow{R_{i}}\right)\right\|$, and the weighted off-inferior distance can be defined as $u_{i}^{c}\left\|\vec{W}\left(\overrightarrow{R_{i}}-\vec{B}\right)\right\|$.

The objective function of an optimal criterion is defined as that the sum of the square of the weighted off-inferior distance and the square of the weighted off-optimal distance of each gas reservoir takes the minimum value, namely:

$$
\min \left\{F\left(u_{i}\right)=\sum_{i=1}^{n}\left[\left(u_{i}\left\|\vec{W}\left(\vec{G}-\overrightarrow{R_{i}}\right)\right\|\right)^{2}+\left(\left(1-u_{i}\right)\left\|\vec{W}\left(\overrightarrow{R_{i}}-\vec{B}\right)\right\|\right)^{2}\right]\right\}
$$

where $u_{i}$ represents the membership degree of the $i$-th gas reservoir $x_{i}$ to the optimal fuzzy set, $\vec{G}$ represents the membership degree matrix of the optimal gas reservoir, $\vec{B}$ represents the membership degree matrix of the inferior gas reservoir, $\vec{W}$ represents the index weight matrix, and $\vec{R}_{i}$ represents the membership degree matrix of the $i$-th gas reservoir

Take the derivation for the objective function (10) and assume the derivation to be equal to 0 , namely:

$$
d F\left(u_{i}\right) / d u_{i}=0
$$

$$
\begin{aligned}
& u_{i}\left(\|\vec{W}(\vec{G}-\vec{R})\|^{2}+\left\|\vec{W}\left(\overrightarrow{R_{i}}-\vec{B}\right)\right\|^{2}\right)=\left\|\vec{W}\left(\overrightarrow{R_{i}}-\vec{B}\right)\right\|^{2}, \\
& u_{i}=\left\{1+\left[\frac{\|\vec{W}(\vec{G}-\vec{R})\|}{\left.\left\|\vec{W}\left(\overrightarrow{R_{i}}-\vec{B}\right)\right\|\right]^{2}} .\right.\right.
\end{aligned}
$$
follows:

Thus, the fuzzy screening model can be obtained as

Then,

$$
u_{i}=\left\{1+\left[\frac{\|\vec{W}(\vec{G}-\vec{R})\|}{\left\|\vec{W}\left(\overrightarrow{R_{i}}-\vec{B}\right)\right\|}\right]^{2}=\left\{1+\left[\frac{\sum_{j=1}^{m}\left[\omega_{j}\left(g_{i j}-r_{i j}\right)\right]}{\sum_{j=1}^{m}\left[\omega_{j}\left(r_{i j}-b_{1 j}\right)\right]}\right]^{2}\right\}^{-1} .\right.
$$

Equation (17) is the fuzzy optimization theory model for gas reservoir evaluation and optimization.

\subsection{Gas Reservoir Evaluation and Optimization Model.} There are numerous factors that affect the evaluation results of gas reservoirs, but it is difficult to evaluate each influencing factor. Based on the quantitative study on the evaluation parameters in fuzzy mathematics, a suitable comprehensive analysis method for gas reservoir evaluation and optimization is proposed in this paper.
3.2.1. Gas Reservoir Index Suitability Degree. The fuzzy membership degree of the $j$-th evaluation index of the $i$-th gas reservoir $\left(P_{i j}\right)$ to the optimal value, $x_{i j} \in(0,1)$, can be calculated by the following:

$$
x_{i j}=\left|\frac{P_{i j}-P_{o j}}{P_{w j}-P_{o j}}\right|,
$$

where $P_{o j}$ is the most suitable index value and $P_{w j}$ is the least suitable index value. From (17), it can be inferred that the closer the evaluation index of a gas reservoir is to the optimal ideal value, the smaller the fuzzy membership degree is. 
In order to ensure that the optimal degree of membership can take a larger value when the evaluation parameters of the gas reservoir are closer to the optimal ideal values and meanwhile enlarge the differences among different evaluation indexes, an exponential function as follows is introduced:

$$
a_{i j}=e^{-4.6 x_{i j}^{2}} .
$$

Thus, the fuzzy suitability degree of each evaluation index can be converted into $a_{i j}, a_{i j} \in(0,1)$. When the value of $a_{i j}$ is larger and closer to 1 , this index is better. Hence, the fuzzy suitability matrix $A$ of each gas reservoir can be expressed by using $a_{i j}$ as the evaluation index. Each element of the fuzzy suitability matrix A reflects the suitability degree of each index of a certain candidate gas reservoir and the differences of the suitability degree of the same evaluation index among different gas reservoirs.

3.2.2. Establishment of the Comprehensive Evaluation and Screening Method. After establishing the suitability degree matrix $A\left(a_{i j}\right)$ for $m$ evaluation indexes of $n$ gas reservoirs, the weight vector $\omega_{j 1}$ for evaluating the degree of influence of each index considering the different influence degrees of different indexes on the evaluation results of gas reservoirs is required.

The product of element $a_{i j}$ in the fuzzy membership matrix $A_{i j}$ and the weight transposition matrix of each index $\omega_{1 j}^{T}$, which is denoted as $W_{i 1}$, can be used to reflect the weighted performance of the degree of suitability of the gas reservoir evaluation parameters, namely:

$$
W_{i 1}=A_{i j} \cdot \omega_{1 j}^{T} .
$$

The product of $W_{i j}$ and the weighted matrix $\omega_{1 j}$, which is denoted as $M_{i j}$, can reflect the differences in the different evaluation parameters of different gas reservoirs, namely:

$$
M_{i j}=W_{i 1} \cdot \omega_{1 j} .
$$

Hence, equations (21) and (22) can be used to obtain the evaluation and optimization sequence of all gas reservoirs. The comprehensive evaluation results of gas reservoir evaluation and optimization can be ranked according to the values of $V_{i}^{\prime}$ as follows:

$$
\begin{aligned}
& V_{i}^{\prime}=\frac{\sum_{j=1}^{m} M_{i j}}{\sum_{j=1}^{m} M_{1 j}} . \\
& V_{i}=\frac{100 V_{i}^{\prime}}{\sum_{j=1}^{m} V_{i}^{\prime}} .
\end{aligned}
$$

3.2.3. Weight Allocation Method. For the gas reservoir comprehensive evaluation model, it is necessary to obtain the influence weight of each evaluation index in the gas reservoir. The weight of each evaluation index can be obtained by the fuzzy analytic hierarchy process.

Fuzzy analytic hierarchy process (FAHP) is a method to calculate the weights of evaluation indexes by constructing fuzzy judgment, which can reflect the real situation well. The fuzzy judgment matrix $R$ can be established as shown in the following:

$$
R=\begin{array}{ccccc}
C & a_{1} & a_{2} & \cdots & a_{n} \\
a_{1} & r_{11} & r_{12} & \cdots & r_{1 n} \\
a_{2} & r_{21} & r_{22} & \cdots & r_{2 n} . \\
\vdots & \vdots & \vdots & \vdots & \vdots \\
a_{n} & r_{n 1} & r_{n 2} & \cdots & r_{n n}
\end{array}
$$

The meaning of element $r_{i j}$ in the fuzzy judgment matrix is that when the evaluation index $a_{i}$ and the evaluation index $a_{j}$ are compared relative to $C$ (which can be expressed as the recovery factor), the evaluation index $a_{i}$, and the evaluation index $a_{j}$ follow the rule that $a_{i}$ is more important (or less important) than $a_{j}^{\prime \prime}$.

The degrees of importance of the two evaluation indexes relative to $C$ are quantitatively described in Table 1 .

Similarly, the fuzzy membership degrees of the evaluation index $a_{j}$ and the evaluation index $a_{i}$ can be obtained. $r_{i j}$ is defined as the fuzzy membership degree scale of the evaluation index $a_{i}$ to the evaluation index $a_{j}$, and $r_{j i}$ is defined as the fuzzy membership degree scale of the evaluation index $a_{j}$ to the evaluation index $a_{i}$. Then, $r_{i j}$ and $r_{j i}$ have the following relationship:

$$
r_{j i}=1-r_{i j} .
$$

Further, the fuzzy judgment matrix expressed by the fuzzy membership degree scale can be obtained as follows:

$$
R=\left[\begin{array}{cccc}
r_{11} & r_{12} & \cdots & r_{1 m} \\
r_{21} & r_{22} & \cdots & r_{2 m} \\
\vdots & \vdots & \vdots & \vdots \\
r_{m 1} & r_{m 2} & \cdots & r_{m m}
\end{array}\right] .
$$

$R$ has the following properties:

(1) When $i=j, r_{i j}=0.5(i, j=1,2,3, \ldots, m)$

(2) $r_{j i}=1-r_{i j}(i, j=1,2,3, \ldots, m)$

When the fuzzy judgment matrix $R$ is a consistent fuzzy matrix, the weight $\omega_{i}$ can be calculated by the following:

$$
\omega_{i}=\frac{1}{m}-\frac{1}{2 a}+\frac{1}{m a} \sum_{k=1}^{m} r_{i k} .
$$

In equation (26), $a$ represents the difference between the emphasis degrees for different indexes, which is related to the number of evaluation indexes and the degree of difference. When $a=(m-1) / 2$, the weights have the largest difference degree; that is, $a$ is equal to $(m-1) / 2$ when we attach the most important to the importance of evaluation indexes. This value of $a$ is also the used value in our practical applications.

After the weight matrix $\omega_{1 j}=\left[\omega_{1}, \omega_{2}, \ldots, \omega_{i}\right](i=m)$ of all evaluation indexes is obtained, it can be substituted into equations (19)-(21) to prioritize the candidate gas reservoirs. 
TABle 1: Descriptions of the fuzzy judgment matrix ranges.

\begin{tabular}{lccc}
\hline Scale & Definition & Scale & Definition \\
\hline 0.1 & Extremely secondary & 0.6 & Slightly important \\
0.2 & Very secondary & 0.7 & Obviously important \\
0.3 & Obviously secondary & 0.8 & Very important \\
0.4 & Slightly secondary & 0.9 & Extremely important \\
0.5 & Equally important & & \\
\hline
\end{tabular}

\section{Influencing Factors of Gas Reservoir Exploitation Effect}

In order to clearly understand the influences of each influencing factor on the gas reservoir exploitation effect, the numerical simulation model was established by using the numerical simulation technology to preliminarily study the influencing rules.

4.1. Skin Factor. The skin factor affects the conductivity between the well and the grid in the numerical model. The larger the skin factor, the worse the exploitation effect. This is because the skin factor affects the conductivity between the wellbore and the grid in the numerical model. As shown in Figures 2-4, the skin factor indeed has a certain influence on the exploitation effect.

4.2. Stress Sensitivity. In the stress-sensitive formation, with a decrease in the formation pressure, the opened fractures under high pressure gradually close and the permeability also simultaneously decreases. This overall affects the flow of the fluids, especially for a gas reservoir with induced fractures.

Figures 5-7 show the simulation results. Stress sensitivity leads to the shortening of stable production periods and the reduction of final accumulated gas yield, which greatly affects the exploitation effect of gas reservoirs. Hence, for stress-sensitive gas reservoirs, horizontal wells should be used as far as possible to reduce the bottom-hole flow pressure; meanwhile, a reasonable gas production rate should be maintained to avoid the formation of larger pressure drawdown distribution.

4.3. Water Saturation. Water saturation mainly affects the calculation of effective permeability of a gas well, thus affecting the calculation of conductivity. For different watercut models, it can be seen from Figures 8-10 that water saturation has a great influence on stable gas production and accumulative gas production. Therefore, wells should be deployed on the high part of the structure as far as possible so that the perforation segments can be restricted in the regions with high gas saturation as far as possible, thus reducing the risk of water invasion.

4.4. Permeability. Permeability is an important parameter in Darcy's formula, which greatly affects the calculation of conductivity in a numerical simulation. In actual production, permeability has a great influence on the gas well productivity and the gas reservoir exploitation effect. For different permeability models, it can be seen from Figures 11-13 that permeability has a great influence on the stable gas production and accumulative gas production of a gas reservoir. It is considered that permeability is an important index that has a greater influence on the exploitation effect.

4.5. Water Invasion. Water invasion greatly influences gas reservoir production over time. Water invasion can result in a sharp decrease in the gas phase permeability, leading to a decrease in the gas well production capacity. Conversely, water invasion can result in wellbore effusion, and the gas-liquid two-phase flow can increase wellbore friction, thus affecting the gas production ability. Concurrently, the "water encasing gas" phenomenon may appear due to water invasion, making it difficult to exploit this part of the gas reserves. It has been proven in actual production that water invasion has a great influence on the gas reservoir exploitation effect. Figures 14-16 show the numerical simulation results. Once water invasion occurs, the stable production period of the gas reservoir is sharply shortened or even there completely absent. The accumulative gas yield at the end of the forecast period is also greatly reduced. Therefore, water invasion is an important index affecting the gas reservoir exploitation effect.

Based on the above analysis and according to the actual production of gas reservoirs, the above influencing factors are ranked as follows: permeability $>$ water saturation $>$ water invasion $>$ stress sensitivity $>$ skin factor. The ranking of influencing factors obtained by numerical simulation provides a reference basis for the weight allocation of influencing factors. 


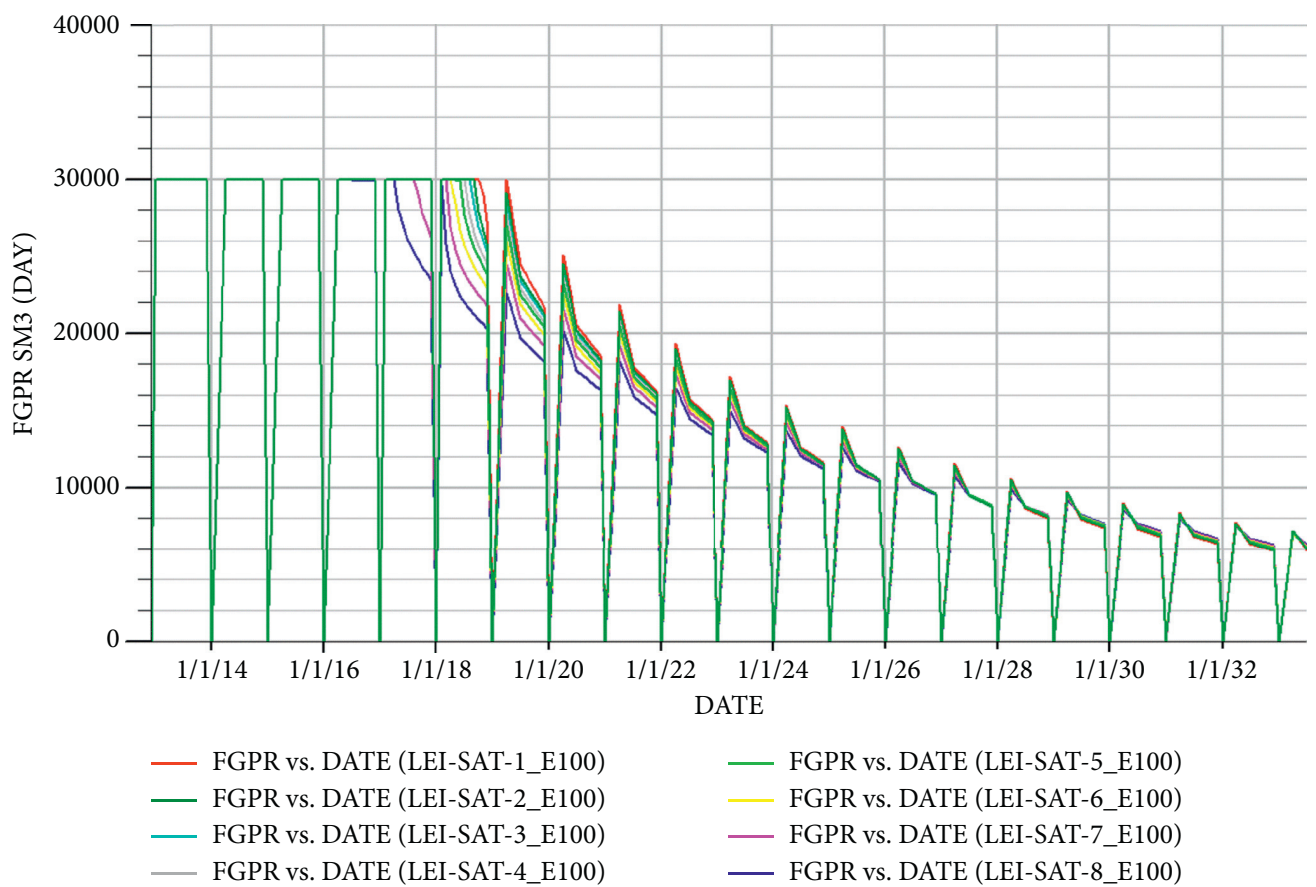

Figure 2: Prognostic map of daily gas yield by the numerical model with different skin factors.

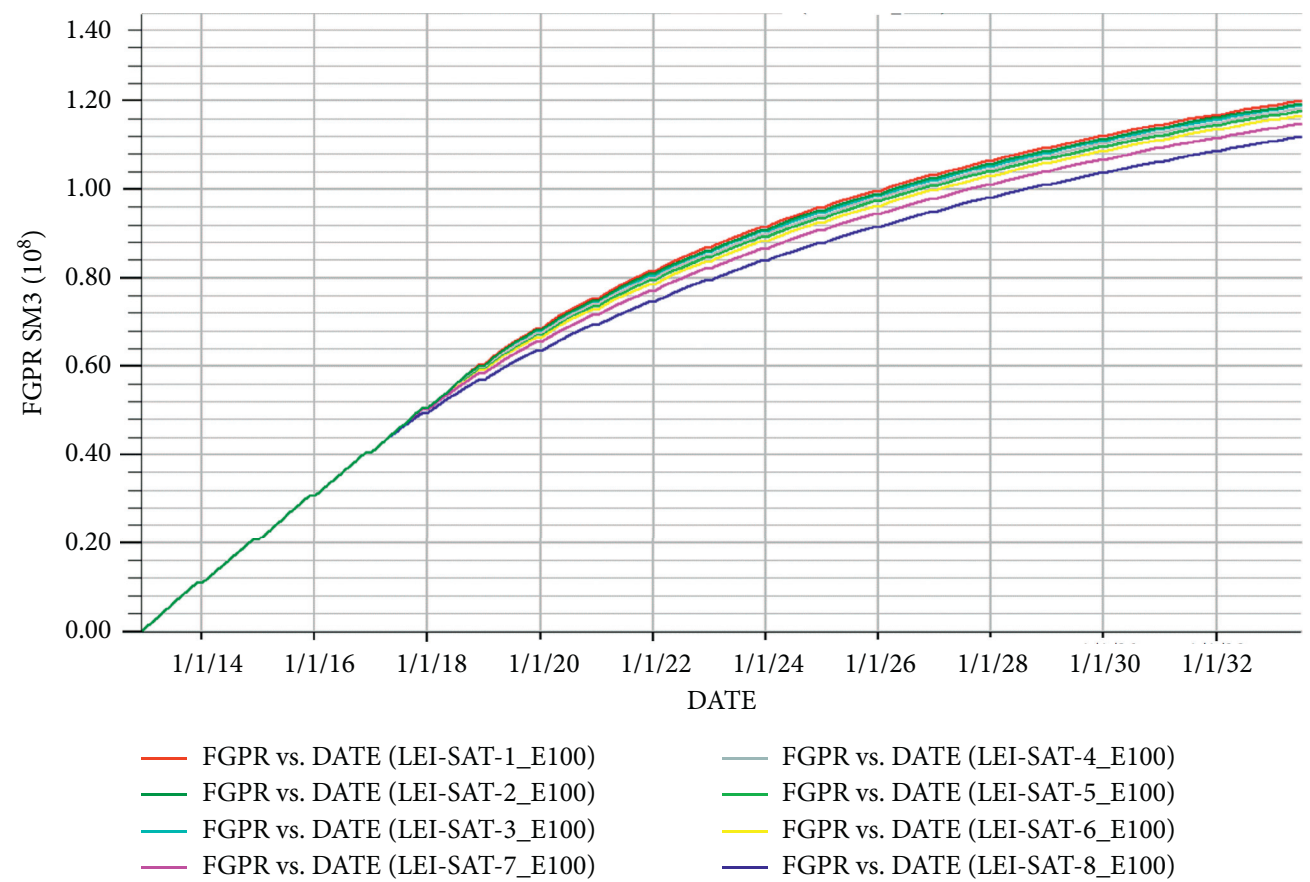

Figure 3: Prognostic map of accumulative gas yield by the numerical model with different skin factors. 


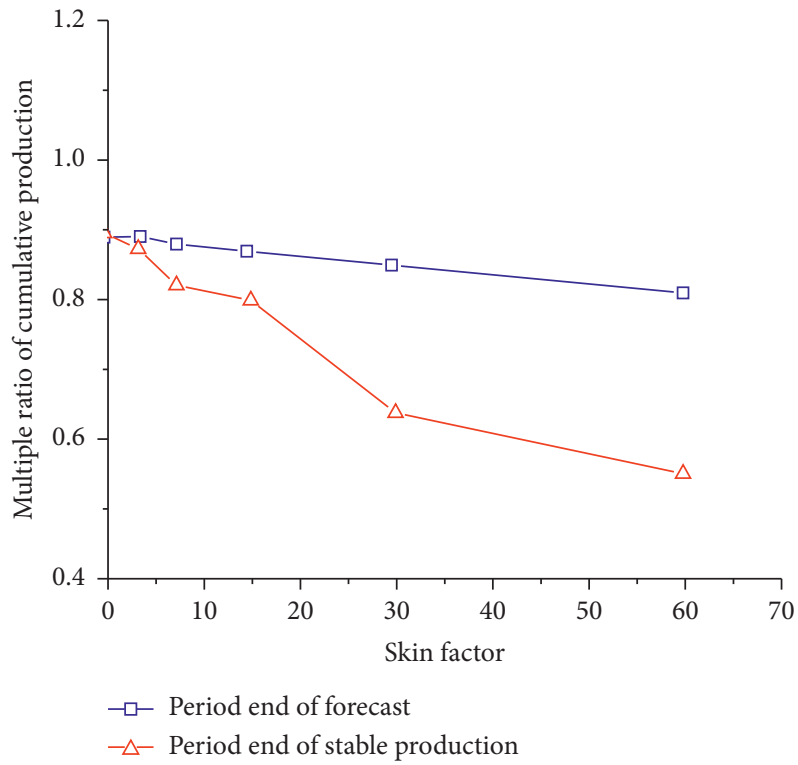

Figure 4: Multiple proportions of gas yield by the numerical model with different skin factors.

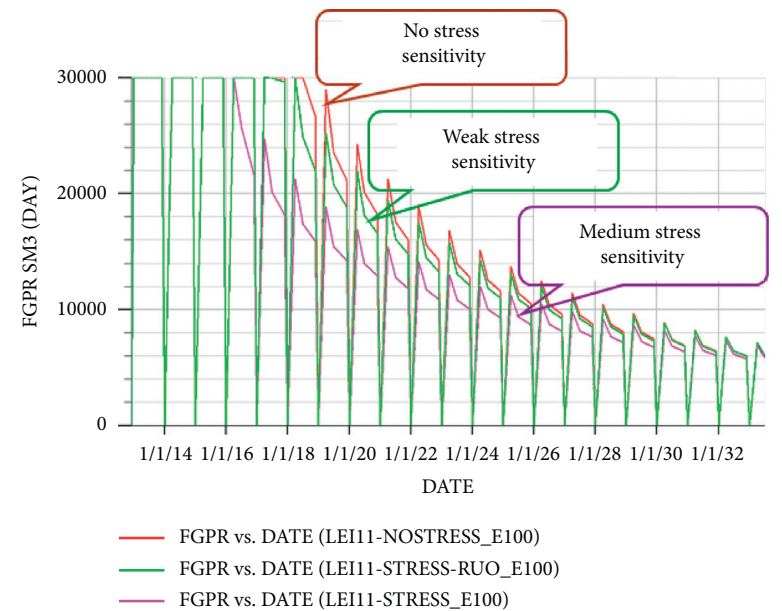

FIGURE 5: Prognostic map of daily gas yield by numerical modeling with different stress sensitivity degrees.

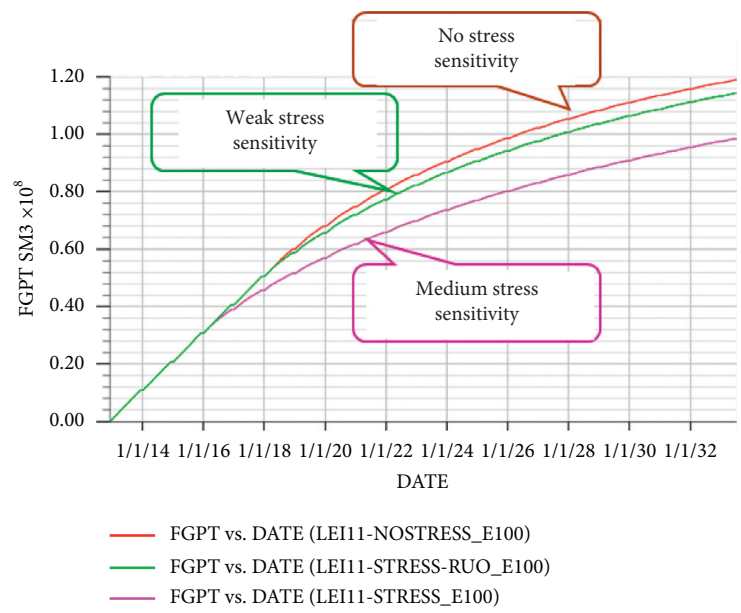

Figure 6: Prognostic map of accumulative gas yield by numerical modeling with different stress sensitivity degrees. 


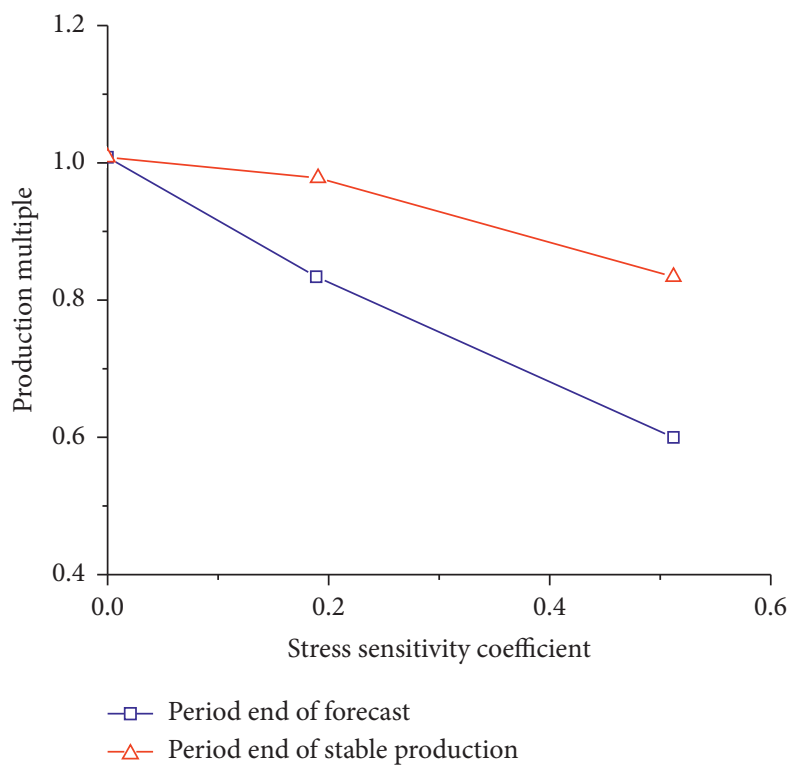

FIGURE 7: Multiple proportions of gas yield by numerical modeling with different stress sensitivity degrees.

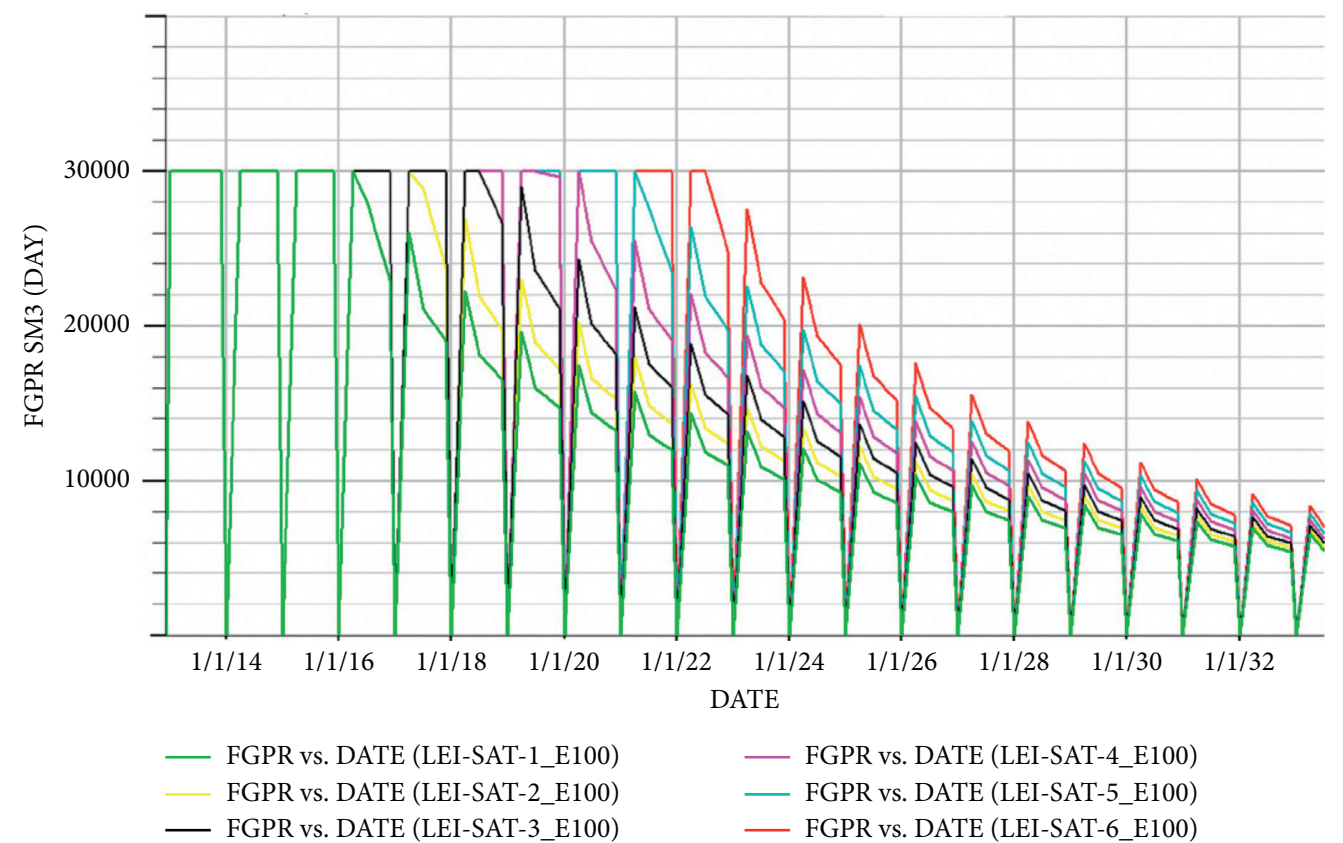

FIGURE 8: Prognostic map of daily gas yield by numerical modeling with different water saturations. 


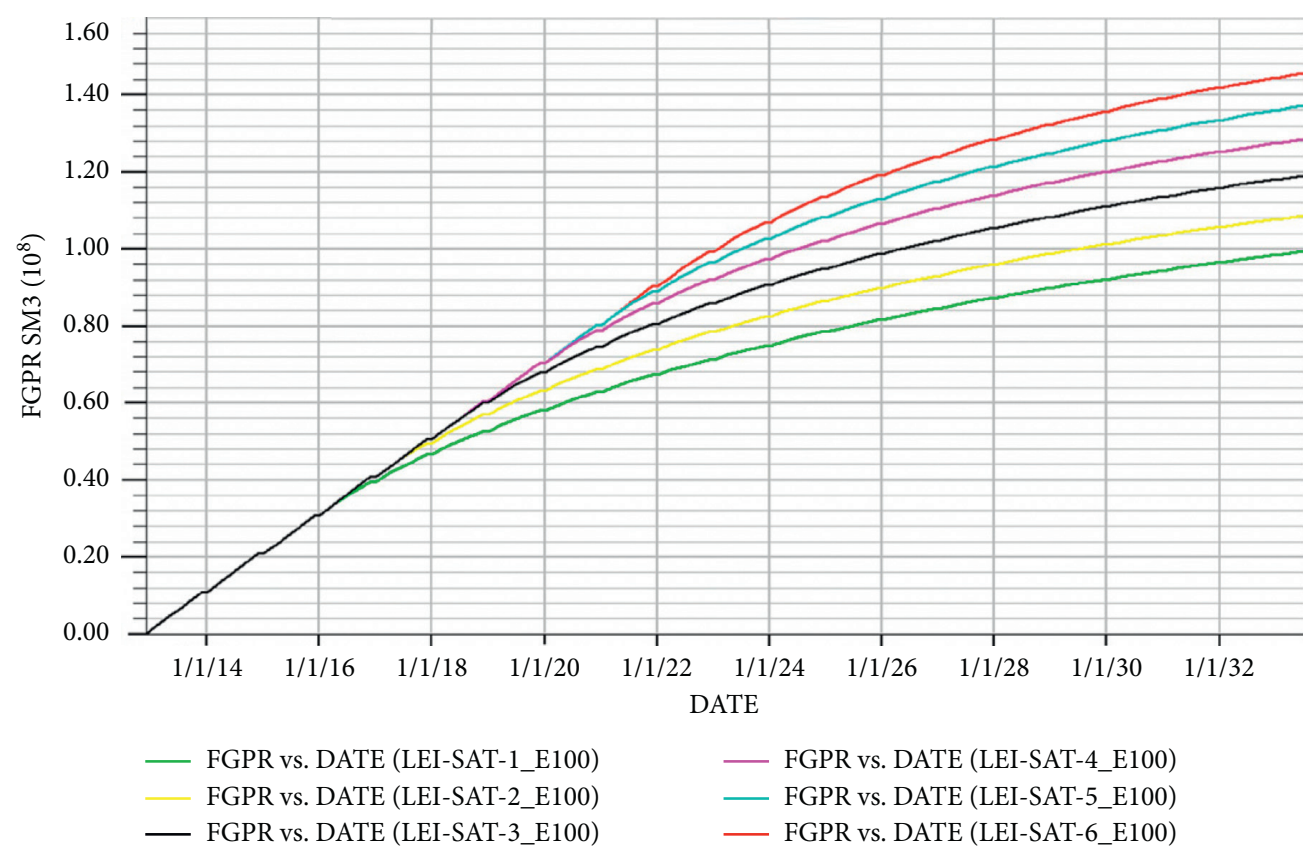

FIgURE 9: Prognostic map of accumulative gas yield by numerical modeling with different water saturations.

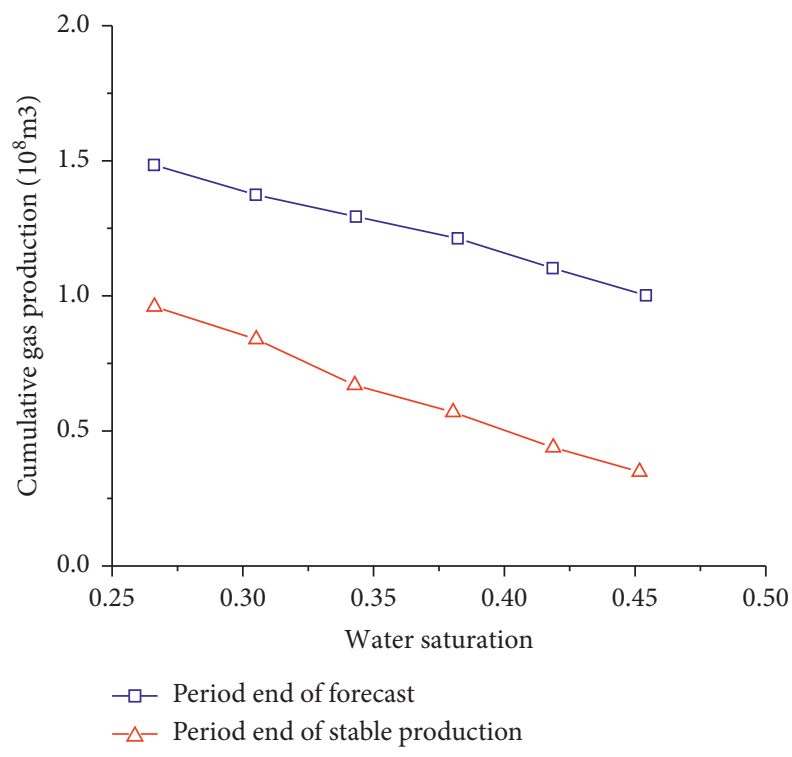

FIGURE 10: Accumulative gas yield map by the numerical model with different water saturations. 


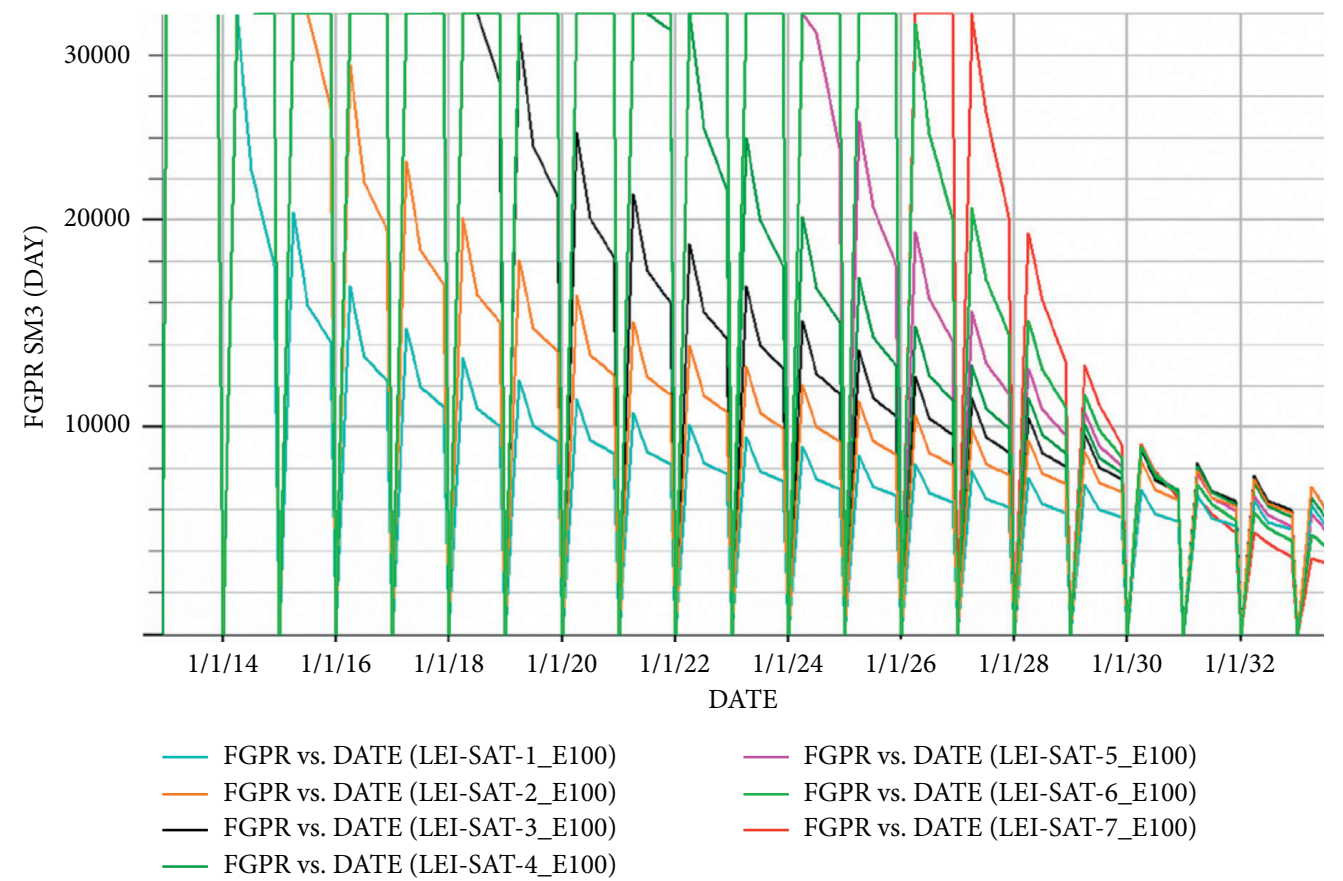

Figure 11: Prognostic map of daily gas yield by numerical modeling with different permeabilities.

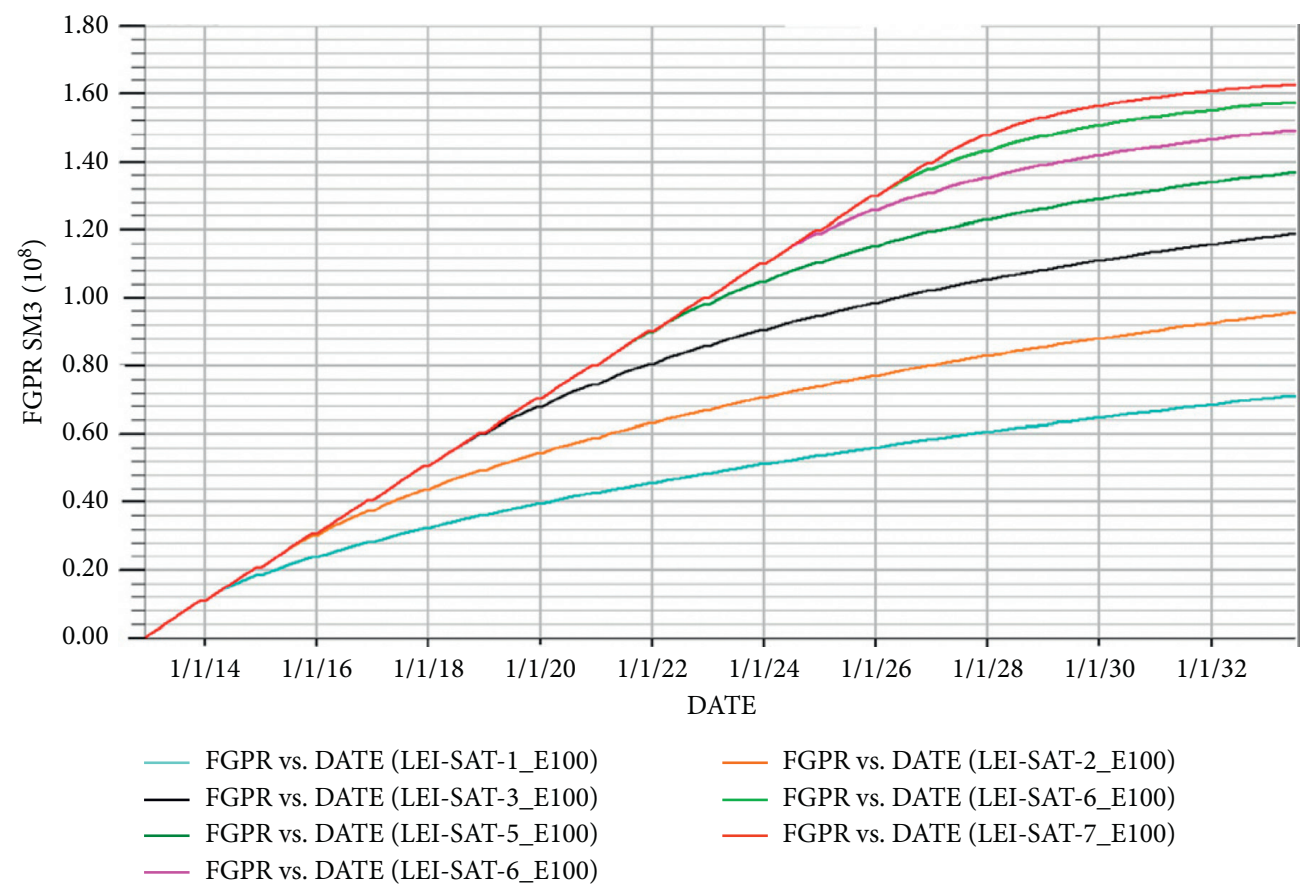

Figure 12: Prognostic map of accumulative gas yield by numerical modeling with different permeabilities. 


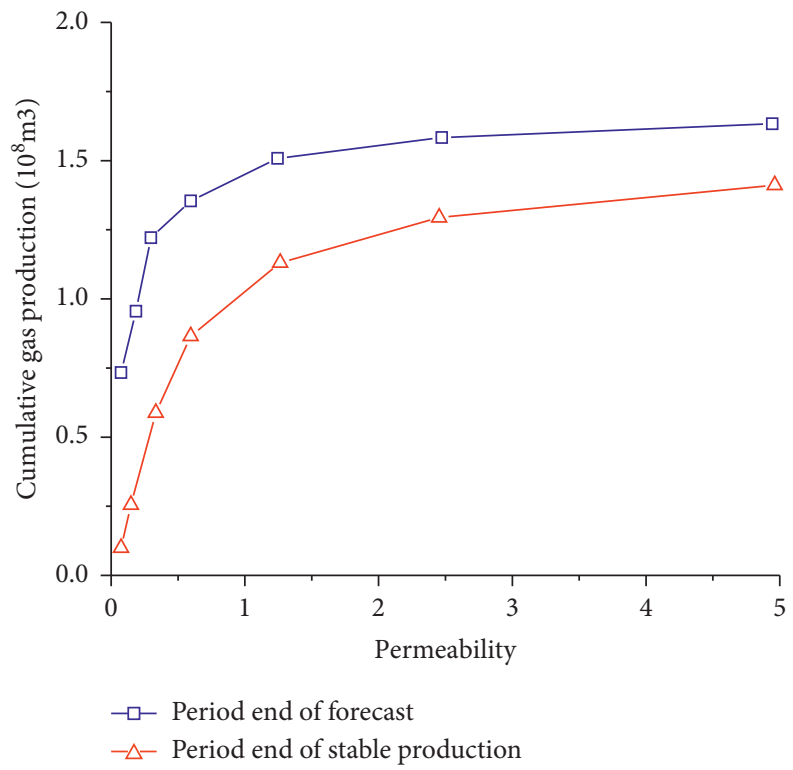

FIgURe 13: Accumulative gas yield map by numerical modeling with different permeabilities.

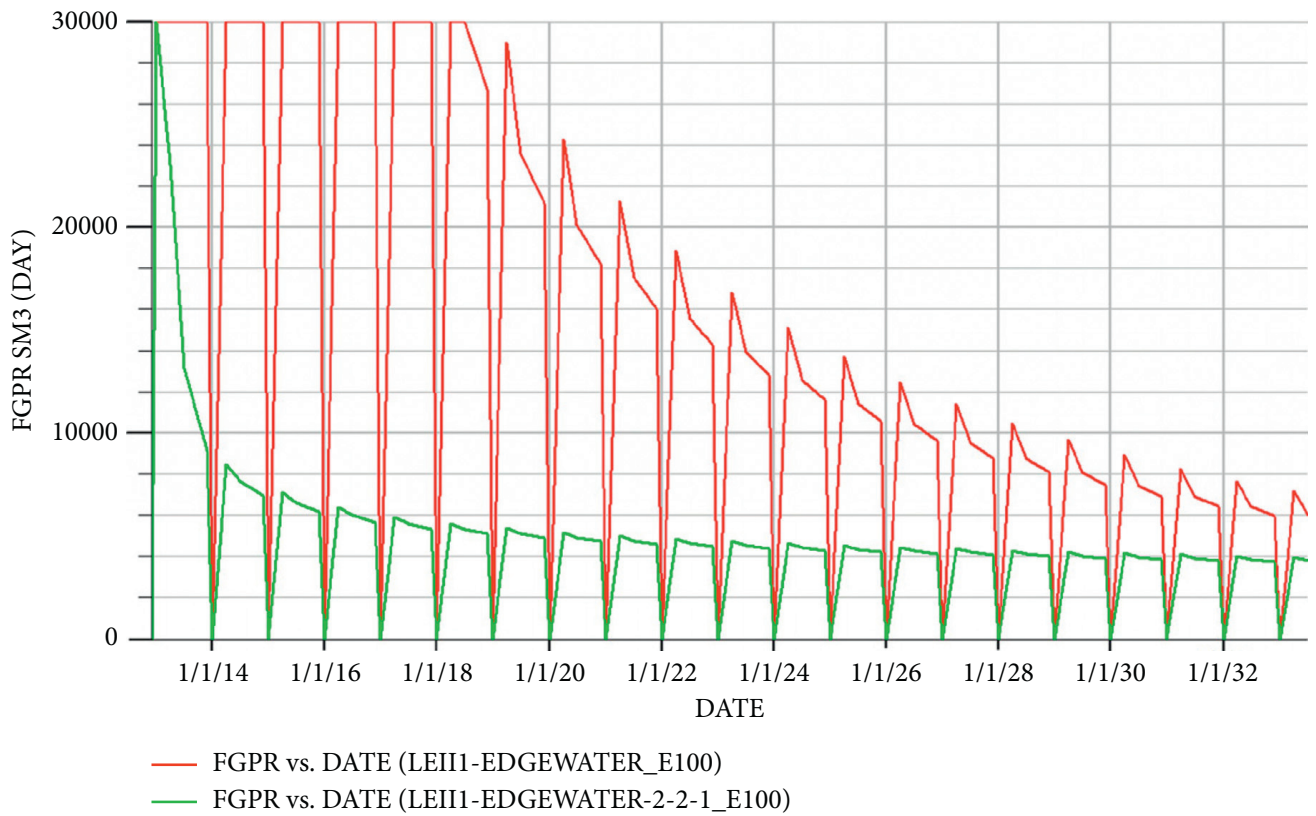

FIgURe 14: Prognostic map of daily gas yield by numerical modeling with and without water invasion. 


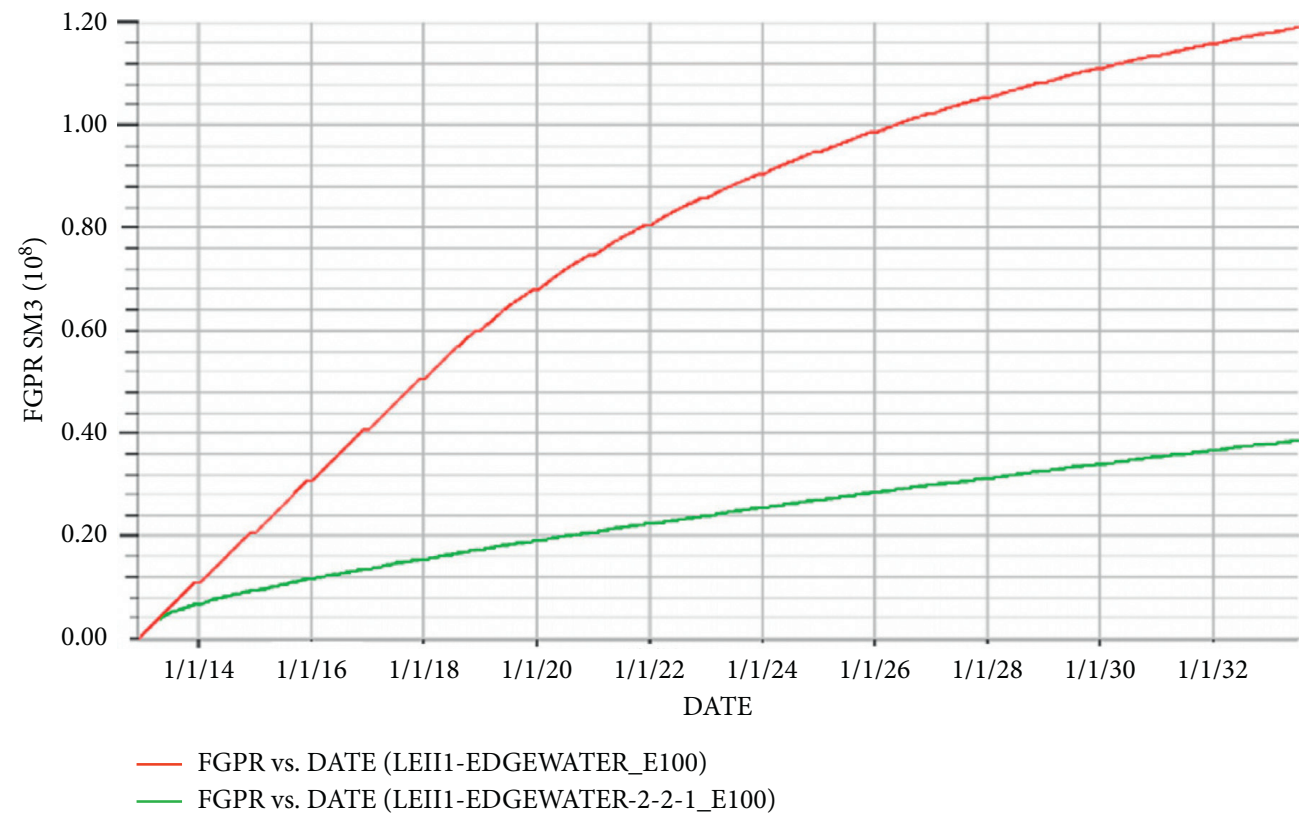

Figure 15: Prognostic map of accumulative gas yield by numerical modeling with and without water invasion.

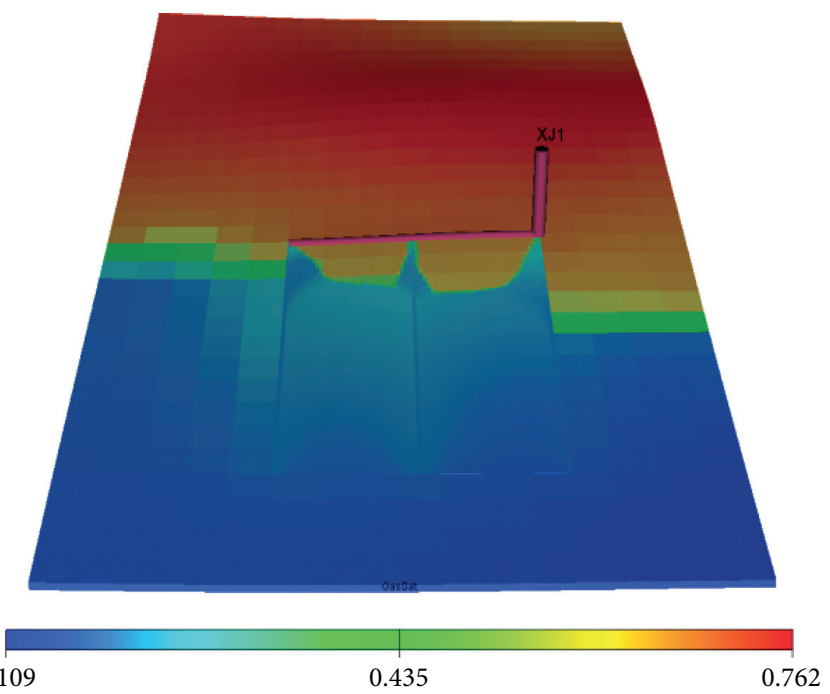

FIgURE 16: Water saturation map at the end of the forecast period by numerical modeling with water invasion.

\section{Conclusions}

In order to further analyze key indexes that affect a gas reservoir during production, this paper considered the characteristic parameters of different types of gas reservoirs and established an index system of evaluating a gas reservoir "exploitation effect" from the three aspects of gas reservoir characteristics, rock characteristics, and economic benefits.

There are numerous factors affecting the exploitation effect of a gas reservoir. The relationships between different factors are complicated, and the evaluation result of each factor can also be vague. A fuzzy optimization theoretical model for gas reservoir evaluation and optimization was established on the basis of a quantitative study on the evaluation parameters in fuzzy mathematics.
In order to clearly understand the influence of each factor on the gas reservoir exploitation effect, numerical simulation was used to perform a multifactor numerical simulation study of the quantitative sensitivity to determine the sequence of different influencing factors in terms of influencing the gas reservoir exploitation effect.

\section{Data Availability}

The data used to support the findings of this study are available from the corresponding author upon request.

\section{Conflicts of Interest}

The authors declare that there are no conflicts of interest. 


\section{Acknowledgments}

This research was financially supported by the National Science and Technology Major Project (2016ZX05045).

\section{References}

[1] G. Guo and R. D. Evans, "An economic model for assessing the feasibility of exploiting naturally fractured reservoirs by horizontal well technology," in Proceedings of the SPE Annual Technical Conference and Exhibition, Houston, TX, USA, October 1993.

[2] S. O. Osisanya, "Economic analysis of horizontal wells. revista do instituto de medicina tropical de são paulo," revista do instituto de medicina tropical de são paulo, 1997.

[3] B. Liu, Y. Xu, F. J. Guo, and H. Huang, "Study on economic evaluation method of horizontal well deployment," Special Oil \& Gas Reservoirs, vol. 18, no. 01, pp. 68-70+142, 2011.

[4] Y. F. Wang, C. C. Liu, and L. Liu, "Practice and understanding of differential development of tight sandstone gas reservoir in Western Sichuan depression: a case study of J2s2 gas reservoir in Xinchang," Natural Gas Industry, vol. 39, no. S1, pp. 174-178, 2019.

[5] H. Z. Wu, Z. P. Li, and G. M. Ke, "Characteristics of the Changxing Fm biohermal gas reservoir in the Yuanba Gas field, Sichuan Basin and development countermeasures," Natural Gas Industry, vol. 36, no. 9, pp. 11-19, 2016.

[6] Z. B. Wang, X. W. Sun, and X. J. Xiao, "High efficient development technology of fractured tight sandstone gas reservoir with ultra deep and ultra high pressure: a case study of Kelasu gas field in Tarim Basin," Natural Gas Industry, vol. 38, no. 04, pp. 87-95, 2018.

[7] H. Dong, J. Sun, L. Cui, N. Golsanami, and W. Yan, "Characteristics of the pore structure of natural gas hydrate reservoir in the Qilian Mountain Permafrost, Northwest China," Journal of Applied Geophysics, vol. 164, pp. 153-159, 2019.

[8] J. Ding, Y. Cheng, C. Yan, B. Song, H. Sun, and F. Teng, "Experimental study of sand control in a natural gas hydrate reservoir in the South China sea," International Journal of Hydrogen Energy, vol. 44, no. 42, pp. 23639-23648, 2019.

[9] Y. F. Sun, J. Zhong, and G. Chen, "A new approach to efficient and safe gas production from unsealed marine hydrate deposits," Applied Energy, vol. 282, Article ID 116259, 2021.

[10] H. Wang, X. Li, H. Sun, G. Meng, W. Cao, and S. Zhu, "Reserve estimation from early time production data in geopressured gas reservoir: gas production of cumulative unit pressure drop method," Geofluids, vol. 2021, Article ID 9926983, 10 pages, 2021.

[11] Y. Hu, Q. Li, L. X. Li, and D. Hu, "Development technology progress and development direction of deep marine carbonate gas reservoir in Sichuan Basin," Natural Gas Industry, vol. 39, no. 09, pp. 54-63, 2019.

[12] X. Z. Wang, X. Y. Qiao, N. Z. Mi, and R. G. Wang, "Technologies for the benefit development of low-permeability tight sandstone gas reservoirs in the Yan'an Gas Field, Ordos Basin," Natural Gas Industry, vol. 39, no. 09, pp. 54-63, 2019.

[13] J. B. Li, B. Fu, Z. J. Zhao, Z. X. Ma, Y. J. Zhu, and X. N. Wu, "Characteristion technology for tight sandstone gas reservoir in the Sulige Gas Field, Ordos Basin, and its development prospect," Natural Gas Industry, vol. 35, no. 12, pp. 35-41, 2015.

[14] H. Yang, J. H. Fu, X. S. Liu, and L. Y. Fan, "Formation conditions and exploration technology of large-scale tight sandstone gas resrvior in Sulige," Acta Petrolei Sinica, vol. 33, no. z1, pp. 27-36, 2012.

[15] Y. J. Zhu, J. B. Li, L. Chen et al., "Key technology of large-wellgroup stereoscopic development in Sulige gasfield," Acta Petrolei Sinica, vol. 39, no. 2, pp. 208-215, 2018.

[16] M. F. He, X. Ma, Y. M. Zhang, X. A. Lai, Y. X. Xiao, and R. F. Hao, "A factory fracturing model of multi-well cluster in Sulige gas field, NW China," Petroleum Exploration and Development, vol. 41, no. 3, pp. 349-353, 2014.

[17] S. Q. Xiao, L. L. Fan, Y. B. Shang, and D. Han, "Application analyse of downhole choking technology in sulige gas field," Pertochemican Industry Application, vol. 29, no. 1, pp. 34-38, 2010.

[18] S. M. Yu and J. F. Tian, "Application of drainage gas recovery technology in sulige gas field and its de-velopment," Drilling \& Production Technology, vol. 40, no. 5, pp. 40-43, 2012.

[19] X. Hao, Y. Wei, K. Yang et al., "Anisotropy of crack initiation strength and damage strength of coal reservoirs," Petroleum Exploration and Development, vol. 48, no. 1, pp. 243-255, 2021.

[20] Y. Zheng, C. Chen, T. Liu, and Z. Ren, "A new method of assessing the stability of anti-dip bedding rock slopes subjected to earthquake," Bulletin of Engineering Geology and the Environment, vol. 80, no. 5, pp. 3693-3710, 2021.

[21] R. R. Jiang, Y. Liu, and K. G. Liao, "Defining a reasonable declining rate in reserves-listed assessment: examples from tight sandstone gas reservoirs of Xujiahe Formation, Xichang gasfield, Sichuan Basin," NATURAL GAS EXPLORATION AND DEVELOPMENT, vol. 44, no. 03, pp. 96-101, 2021.

[22] J. Zhao, B. S. Wu, Y. L. Wu, X. J. Zhao, and W. Z. Chen, Classification and Evaluation of Effective Reservoirs in Deep Tight Sandstone Gas Reservoirsin, pp. 1-10, Journal of Southwest Petroleum University (Science \& Technology Edition, China, 2021.

[23] J. L. Liu, Z. Q. Hu, Z. Q. Liu et al., "Gas pool sweet spot models and their forming mechanism in the xu 2 member in Xinchang area, western sichuan depression, sichuan basin," Oil \& Gas Geology, vol. 42, no. 04, pp. 852-862, 2021.

[24] H. R. Zheng, Z. Q. Liu, S. L. Xu et al., "Progress and key research direction of tight gas exploration and development in Xujiahe Formation, Sinopec exploration areas, Sichuan Basin,” Oil \& Gas Geology, vol. 42, no. 04, pp. 765-783, 2021.

[25] Y. L. Su, X. Y. Li, L. Li et al., "Gas-water two-phase percolation mechanism in tight gas reservoirs based on NMR visualization experiment," Journal of China University of Petroleum(Edition of Natural Science), vol. 45, no. 05, pp. 104-112, 2021.

[26] C. Liu, D. M. Zhang, C. Li, Y. Y. Lu, S. S. Yu, and M. Q. Guo, "Upper Paleozoic tight gas sandstone reservoirs and main controls, Linxing block, Ordos Basin," Oil \& Gas Geology, vol. 42, no. 05, pp. 1146-1158, 2021.

[27] Z. Y. Xie, C. L. Yang, J. Li et al., "Accumulation characteristics and large-medium gas reservoir-forming mechanism of tight sandstone gas reservoir in Sichuan Basin:Case study on the Upper Triassic Xujiahe Formation gas reservoir in central Sichuan Basin," NATURAL GAS GEOSCIENCE, vol. 32, no. 08, pp. 1201-1211, 2021.

[28] X. Peng and Z. T. Wang, "Application effect analysis of resolution spectrum processing technology in tight sandstone gas reservoir decelopment," Jouranl of Geological Hazards and Environment Preservation, vol. 32, no. 02, pp. 72-77, 2021.

[29] L. Wang, Y. M. He, Q. Wang, M. M. Liu, and X. Jin, "Improving tight gas recovery from multi-pressure system during commingled production: an experimental investigation[J]," Natural Resources Research, vol. 30, no. 5, pp. 1-22, 2021. 
[30] M. Ma, J. Yapcheptoyek, A. F. Li et al., "Investigations of water saturation and fractal characteristics in tight sandstone gas reservoirs using centrifugation and NMR experiments," International Journal of Oil, Gas and Coal Technology, vol. 26, no. 4, 2021.

[31] J. Miao and C. Zhong, "Dynamic variation of water saturation and its effect on aqueous phase trapping damage during tight sandstone gas well production," ACS Omega, vol. 6, no. 8, pp. 5166-5175, 2021.

[32] B. Jiu, W. Huang, Y. Li, and M. He, "Influence of clay minerals and cementation on pore throat of tight sandstone gas reservoir in the eastern Ordos Basin, China," Journal of Natural Gas Science and Engineering, vol. 87, Article ID 103762, 2021. 